\title{
Erratum to: Odour supported place cell model and goal navigation in rodents
}

\author{
Tomas Kulvicius • Minija Tamosiunaite • James Ainge • \\ Paul Dudchenko $\cdot$ Florentin Wörgötter
}

Published online: 27 February 2010

(C) Springer Science+Business Media, LLC 2010

\section{Erratum to: J Comput Neurosci}

\section{DOI 10.1007/s10827-008-0090-x}

The original version of this article should have the following acknowledgement:

"FW and TK acknowledge financial support by the German Ministry for Education and Research (BMBF) via the Bernstein Center for Computational Neuroscience (BCCN) Göttingen under Grant No. 01GQ0432."

\section{Action Editor: Wulfram Gerstner}

The online version of the original article can be found at http://dx.doi. org/10.1007/s10827-008-0090-x.

\section{T. Kulvicius $(\varangle) \cdot F$. Wörgötter}

Bernstein Center for Computational Neuroscience,

University Göttingen,

Göttingen, Germany

e-mail: tomas@bccn-goettingen.de

F. Wörgötter

e-mail: worgott@bccn-goettingen.de

T. Kulvicius $\cdot$ M. Tamosiunaite

Department of Informatics, Vytautas Magnus University,

Vileikos 8, 44404 Kaunas, Lithuania

M. Tamosiunaite

e-mail: m.tamosiunaite@if.vdu.lt

J. Ainge $\cdot$ P. Dudchenko $\cdot$ F. Wörgötter

Department of Psychology, University of Stirling,

Stirling FK9 4LA, Scotland 